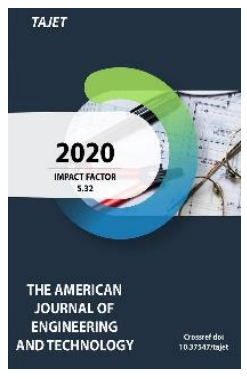

Copyright: Original content from this work may be used under the terms of the creative commons attributes 4.0 licence.

\section{Kinetics Of Fruit Crops Drying With Instant Pressure Release}

\section{Rustamov E.S.}

Doctoral Student, Bukhara Engineering-Technological Institute, Uzbekistan

Djuraev Kh.F.

Professor, Bukhara Engineering-Technological Institute, Uzbekistan

Gafurov K.Kh.

Associate Professor, Bukhara Engineering-Technological Institute, Uzbekistan

\title{
ABSTRACT
}

The article covers results of research of drying process of apricot fruits by the method of three-stage energy supply. The main stages of drying have been defined, including: pulsed infrared heating, instantaneous pressure impact, convective drying. Optimal technological parameters of energy supply in the process of drying apricot fruits at each stage have been developed. The choice of the method for the experimental determination of the drying speed by the parameters of the drying agent for the capillary-porous material is substantiated. The sequence of changes in moisture content in a given material under the influence of a three-stage energy supply is described. The conditions for drying fruits are established and the values of the drying speed in the first period for various methods of energy supply have been selected.

\section{KEYWORDS}

Drying, fruits, apricot, pressure release, kinetics of drying, drying speed, moisture content, porous structure. 


\section{INTRODUCTION}

In process of drying materials, the pressure value determines the depth of its heat treatment. Due to the gradual increase in pressure, it is possible to change the drying temperature, which ensures the transition of moisture to a free state. Because of this, the boundary between bound and free moisture is shifted towards a lower moisture content when the pressure is released. At moment of pressure release, a rapid advance of moisture occurs throughout the volume of the product, a pressure drop between the center and the surface of the material being processed is aroused, which contributes to the formation of a stream of moisture directed to the surface of the particle in the form of steam. On its way, the vapor-air mixture entrains liquid droplets and is pushed to the surface $[1,2]$.

Depending on the purpose of the process, adiabatic conditions of moisture evaporation lead to a decrease in the temperature of the material, a change in the concentration of liquid by the volume of the material being dried, and a modification or destruction of its structure. When drying with a sharp decrease in pressure under adiabatic conditions, the efficiency of moisture removal from capillary-porous materials significantly increases due to a positive temperature gradient. When the pressure is released in the drying chamber, an overpressure inside the material is formed, which corresponds to the temperature of liquid in the layers of material, in result of which a positive gradient of overpressure across the section of the dried particle is created. Accordingly, with a change in external conditions, pressure release can be achieved [1,2].

Purpose of this research is to remove moisture from a capillary-porous material, i.e. apricot fruit, using a three-stage drying method.

In the proposed drying method, the process of removing moisture from the fruit is carried out in stages $[3,4]$ :
1) the material is pulsed infrared processing in order to soften the porous structure and open micropores;

2) the material is exposed to high pressure with instant release in order to intensify the movement of moisture from the inner layers to the surface;

3) the material is subjected to convective drying.

\section{EXPERIMENTS}

In accordance with the aim of the study, the task to study the kinetics of material drying with instant pressure release was set.

The experiments were carried out in installation, the basis of which is a sealed special chamber, where the material samples under study are placed. The pallet for the material is a container with a mesh bottom (mesh size $6 \times 6 \mathrm{~mm}$, wire diameter $0.6 \mathrm{~mm}$ ), a sample of apricot halves with a layer thickness of 8-10 mm was placed in the pallet. The pallet is placed on angled supports. Infrared generators are placed above the pallet to heat the material. The chamber has a quartz glass window.

The chamber is equipped with a compressed air supply system with automatic support of the set pressure. To remove moisture by pressure relief, the unit has a special valve and receiver. The installation allows heating the sample under pressure up to 10 $\mathrm{MPa}$ and relieving pressure. The sample is heated using IR sources with a power of $1 \mathrm{~kW}$ each.

The unit is equipped with a control system and automatic data collection of indicators of the heating process and pressure relief. The main indicators that allows to control and manage the process are temperature, material moisture and pressure in the chamber.

The product is placed in a sealed system, in which a pressure of 0.2 to $10.0 \mathrm{MPa}$ is created using a compressor. The material is processed for 2-6 
minutes, then the pressure is released with an instant opening of the valve, and the vapor-liquid mixture is removed from the system.

\section{RESULTS OF THE EXPERIMENTS}

To study the kinetics of drying apricot fruits (halves of fruits), we carried out experiments with bringing the air pressure to various values ( $0.4 \mathrm{MPa}$; $0.6 \mathrm{MPa}$ and $0.8 \mathrm{MPa}$ ), created by a compressor with instant pressure release. In all cases, the raw material was previously exposed to pulsed infrared irradiation with a radiation density $\mathrm{q}=1.25 \mathrm{~kW} / \mathrm{m} 2$. The appropriateness of choosing this value of the radiation density is shown in [5]. Then the material was subjected to convective drying under the same conditions. Drying curves were constructed and subjected to comparative analysis (Fig. 1).

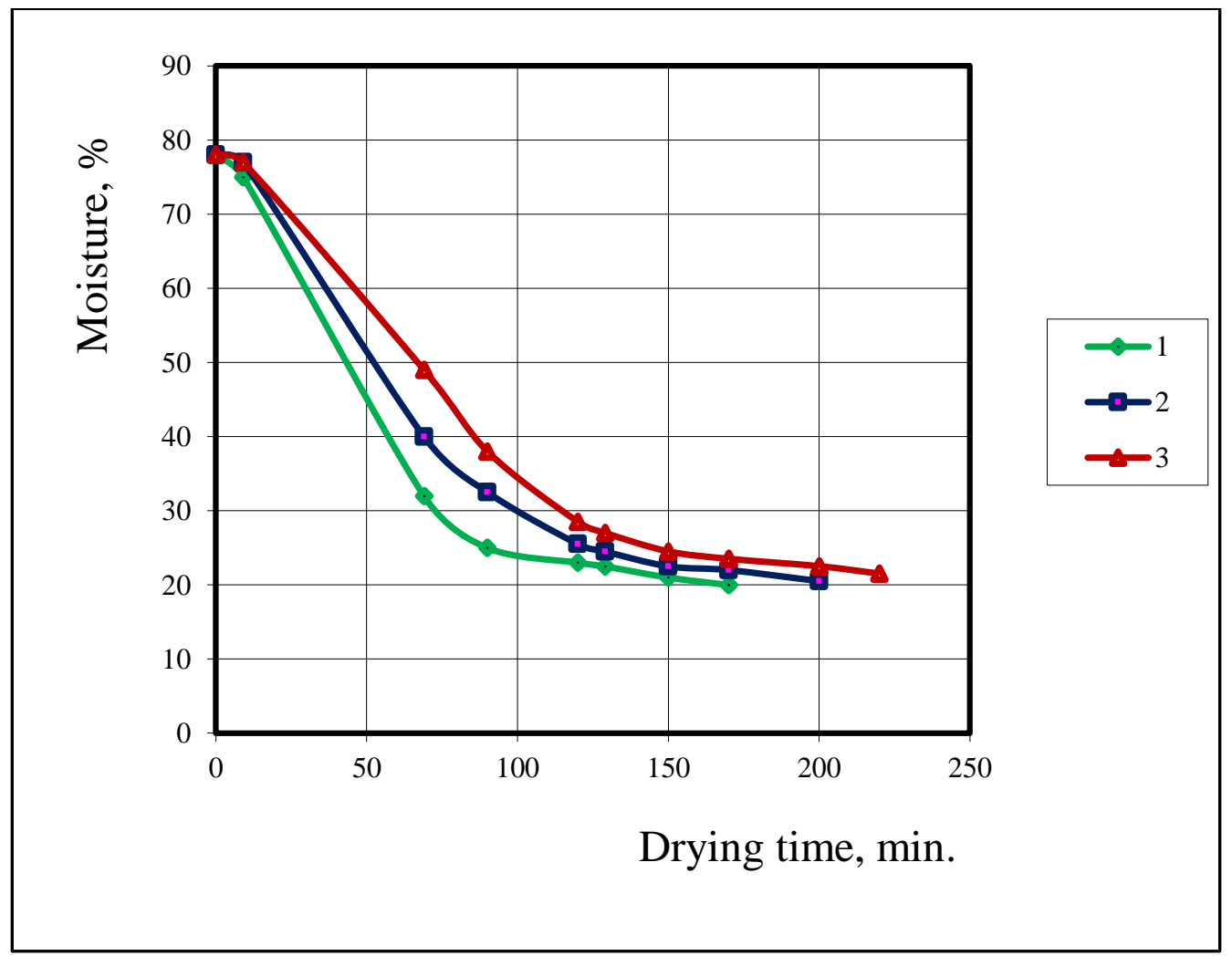

Fig 1. Curves of the kinetics of drying apricot fruit (halves) at different pressure values:

1) $P=0.8 \mathrm{MPa}$, 2) $P=0.6 \mathrm{MPa}$, 3) $P=0.4 \mathrm{MPa} ; q=1.25 \mathrm{~kW} / \mathrm{m}^{2}$.

Initial fruit moisture is $\mathrm{Wi}=78.0 \pm 2.0 \%$, final moisture $\mathrm{Wf}=20.0 \%$.

The curve of fruit drying consists of three stages: heating, constant and decreasing drying speed.
During the heating period, the moisture content of apricot fruits decreases slightly. At the second stage, the moisture content of the fruits decreases intensively with a straight-line dependence. This decrease in moisture is observed until the first critical 
moisture $\omega \mathrm{cr} 1$ is reached, after which a period of decreasing drying speed begins. The inflection point corresponds to the second critical moisture $\omega \mathrm{cr} 2$.

From the curves (Fig. 1) it can be seen that the drying of fruits is more influenced by the pressure created in the working chamber of the drying installation. For example, at a pressure of $\mathrm{P}=0.8 \mathrm{MPa}$ and a thickness $\delta=4 \mathrm{~mm}$ of the product (curve 1 ), the drying process is reduced to $30-40$ minutes compared to the process at a pressure of $\mathrm{P}=0.4 \mathrm{MPa}$ (curve 3 ).

To obtain data on the drying speed of apricot fruits, a tangent at any point of the curve is drawn, the slope of which is equal to the drying speed [6].
According to the results shown in Fig. 2 (curves 1,2), it is possible to compare the kinetic patterns of drying apricots at different pressures. The drying speed at $\mathrm{P}=0.8 \mathrm{MPa}$ is $0.61 \% / \mathrm{min}$, and at $\mathrm{P}=0.4 \mathrm{MPa}$ is 0.42 $\% / \mathrm{min}$. The point $\mathrm{Wcr}$ for $\mathrm{P}=0.8 \mathrm{MPa}$ takes place at Wres $=28 \%$, and for $\mathrm{P}=0.4 \mathrm{MPa}$ at Wres $=40 \%$. Thus, the method of drying the fruit could be chosen at pressure $\mathrm{P}=0.8 \mathrm{MPa}$.

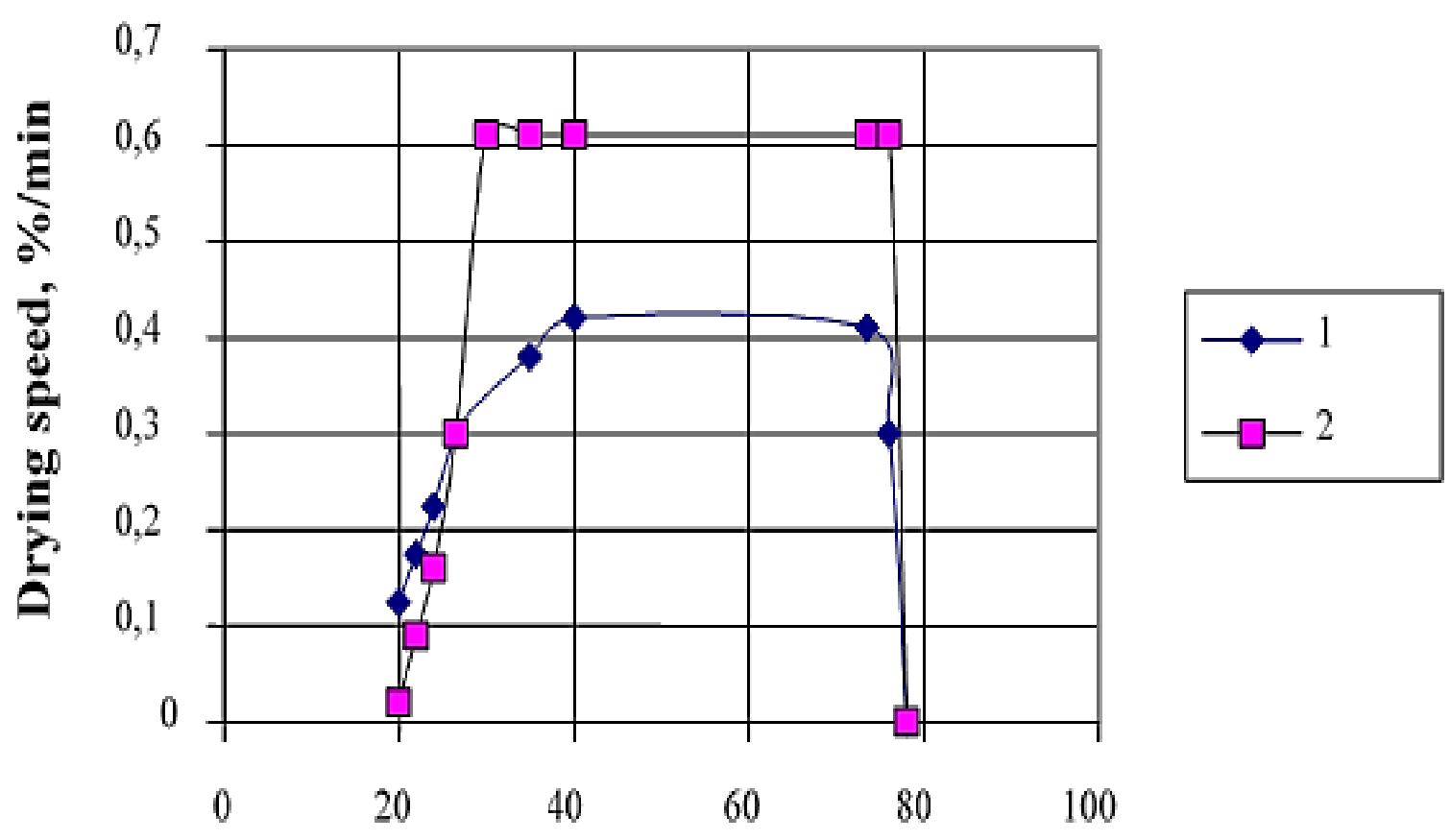

Moisture, $\%$

Fig 2. Curve of the drying speed of apricot fruits (halves)

1- at $P=0.4 \mathrm{MPa} ; 2$ - at $P=0.8 \mathrm{MPa}$.

Density of radiant flux $q=1.25 \mathrm{~kW} / \mathrm{m}^{2}$. 
In order to intensify the drying process of apricot fruits, we carried out experiments on drying under infrared convection. The study of the process was carried out in the following modes:

1) Drying by convection without pretreatment under pressure in the working chamber at $\mathrm{P}=0.8 \mathrm{MPa}$;
2) Drying by infrared convection with pretreatment under pressure in the working chamber at $\mathrm{P}=0.8 \mathrm{MPa}$.

IR convective drying was carried out at a flux density $q=1.25 \mathrm{~kW} / \mathrm{m} 2$. In this case, the specific load was $=8-10 \mathrm{~kg} / \mathrm{m} 2$. It can be seen from the graph (Fig. 3a) that the drying time for apricot fruits is 4.5 hours, and its final moisture content is $19-20 \%$. Drying time without pre-treatment was 5.5 hours.

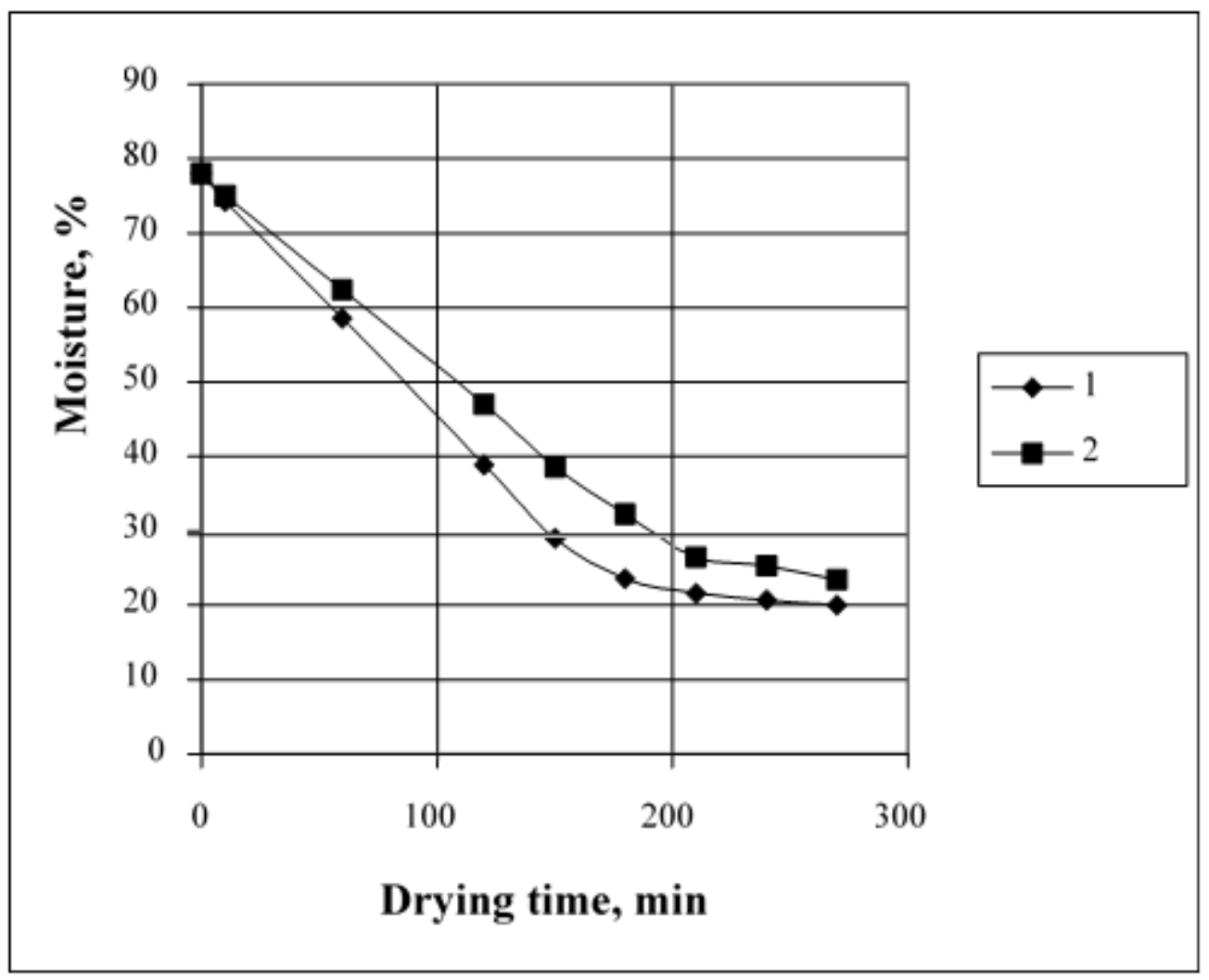

a) 


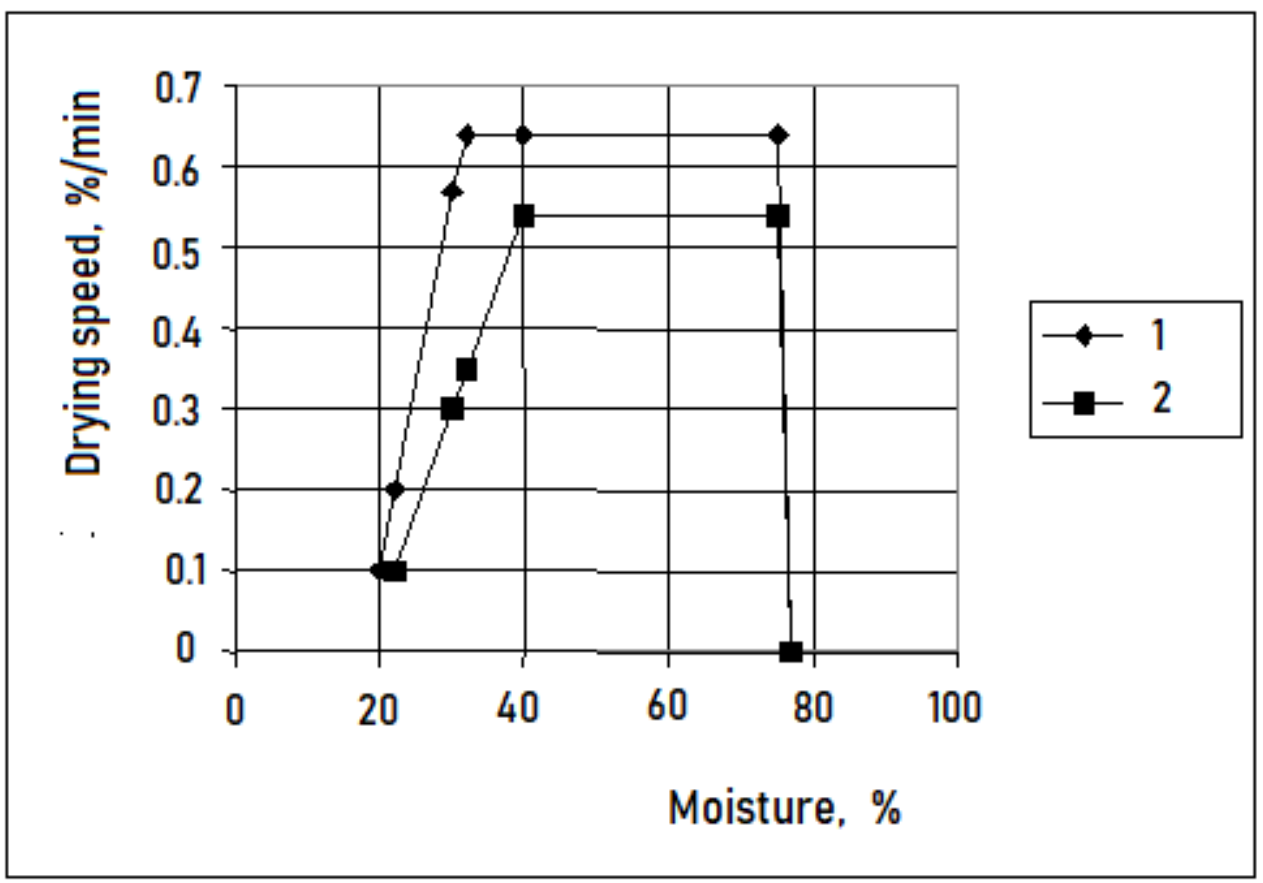

b)

Figure: 3. Curves of drying (a) and speed (b) of apricot fruit drying with various methods

\section{of energy supply:}

1- preliminary treatment with IR-rays in a pulse mode at $P=0.8 \mathrm{MPa}$;

2- without pretreatment at $P=0.8 \mathrm{MPa}$

The apricot drying speed (Fig. 3.b) with pretreatment is $0.65 \% / \mathrm{min}$, the point Wcr1 occurs at $W_{\text {res }}=31.0 \%$, while with no preliminary IR treatment, at $0.55 \% / \mathrm{min}$ Wres $=40.0 \%$.

Comparative experiments on the convective drying of apricot samples with specific energy costs approximately equal to those during drying by pressure release at $\mathrm{P}=0.8 \mathrm{MPa}$ and with the same product thickness were conducted in order to evaluate the effectiveness of the proposed drying method. Data on moisture removal from apricot fruits are presented in Fig. 4. 


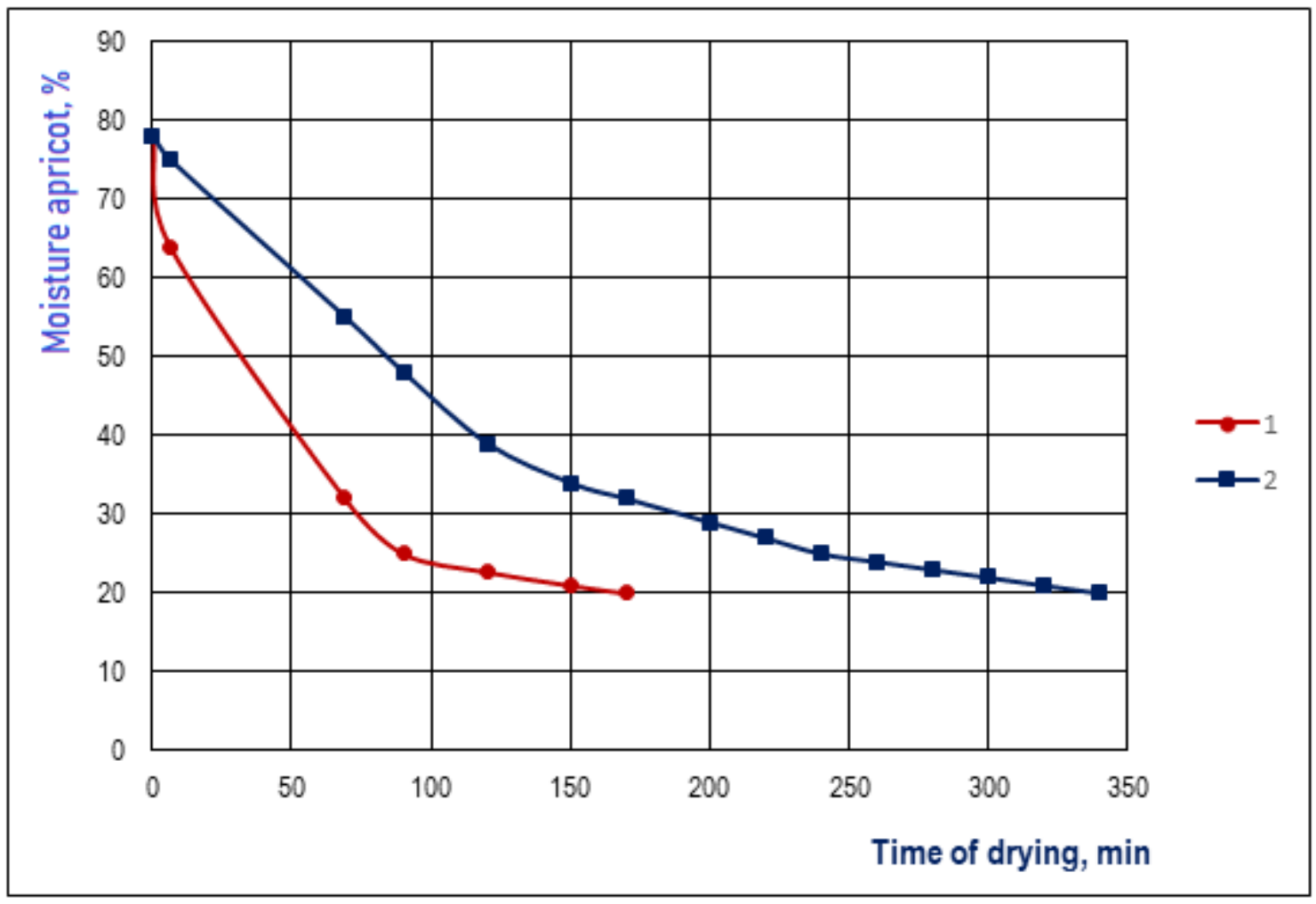

Fig. 4. Kinetics of drying of apricot samples (halves):

1 - method of combined thermomechanical drying at $P=0.8 \mathrm{MPa}$;

2 -convective method

Studies have shown that a product exposed to pressure has a peculiar cellular structure. This means that due to the creation of a certain pressure and its instant release during the drying of the fruit, an intensive movement of moisture occurs between the center and the surface of the material being processed. This, in turn, predetermines the possibility of accelerated movement of moisture from the inner layers of the material to the surface. As a result, the process is accelerated 2.5-3 times than with other existing drying methods.

To find the optimal values of pressure and the time of its instantaneous release within the range $P=2.0 \div 10.0$
$\mathrm{MPa}$, a number of experiments were carried out. By graphically differentiating the drying curve, the dependence of the moisture content of the fruits on the drying speed in various ranges of the generated pressure and the time of its instantaneous release was obtained.

Analysis of the experimental results shows that at a pressure of 2.0 MPa, the cell pores do not open, which leads to uneven drying, and at $4 \mathrm{MPa}$, the product is under dried. Experimental studies have shown that when drying the product without IR exposure, the air temperature does not affect the drying speed $\mathrm{N}$, and 
the $\mathrm{K}$ coefficient increases by $6.7 \%$, the critical moisture decreases by 1.04 times. When processing in the IR-pulse mode, the drying speed increases by $10.0 \%$, the $\mathrm{K}$ coefficient increases by $12.7 \%$, and the critical moisture decreases by 1.2 times. The curves of material drying in two modes shown in Fig. 5. In the range of created pressures of $0.8 \mathrm{MPa}$, the drying speed is $N_{1}=11.2 \cdot 10^{-5} 1 / \mathrm{s}$, and at 6.0 MPa $N_{1}=8.1 \cdot 10^{-5} 1 / \mathrm{s}$. The horizontal line $B C$ indicates the first drying period. The intersection of the curve of the second period with the abscissa axis gives the point $E$ and $E^{\prime}$, which corresponds to the equilibrium moisture content of the dried material $U_{e}=$ $\frac{0,052 \mathrm{~kg}}{\mathrm{~kg}} \mathrm{~d} . \mathrm{m}$ at $\mathrm{P}=0.8 \mathrm{MPa}, U_{e}=\frac{0,052 \mathrm{~kg}}{\mathrm{~kg}} \mathrm{~d} . \mathrm{m}$ at $P=0.6 \mathrm{MPa}$. By replacing the experimental curve in the second period with a straight line drawn from the point $C^{\prime}$ and $C^{\prime \prime}$ we find the critical moisture content. These points on the abscissa give the value of the reduced critical moisture content of the material $U_{c r . r e d}=$ $\frac{0,144 \mathrm{~kg}}{\mathrm{~kg}} \mathrm{~d} . \mathrm{m}$ and $U_{\text {cr.red. }}=\frac{0,24 \mathrm{~kg}}{\mathrm{~kg}} \mathrm{~d} . \mathrm{m}$.

Experimental data obtained for the drying speed in the first period, depending on the generated pressure and the time of instant pressure release in the working chamber of the dryer are presented in Table 2.

Table 2.

\begin{tabular}{|l|l|l|l|l|l|}
\hline$P, M P a$ & 2 & 4 & 6 & 8 & 10 \\
\hline$N \cdot 10^{5}, 1 / c$ & 3.9 & 7.1 & 7.8 & 8.7 & 8.8 \\
\hline
\end{tabular}

\section{CONCLUSIONS}

Analysis results showed that the drying agent is using its full potential with this drying method.

In the proposed drying method, the process of applying pressure and releasing it is quick and takes only 4-12 minutes, while $8-14 \%$ of moisture is removed from its total amount, depending on the pressure generated.

Therefore, the studies carried out using the example of drying apricot fruits show that the proposed drying technology has a number of advantages:

- Reduction of energy consumption for moisture evaporation by 1.7-2.0 times;

- Full utilization of heat in a closed circuit;

- Preservation of biological active substances due to the lowered temperature in the circuit;

- The material consumption of equipment decreases. 


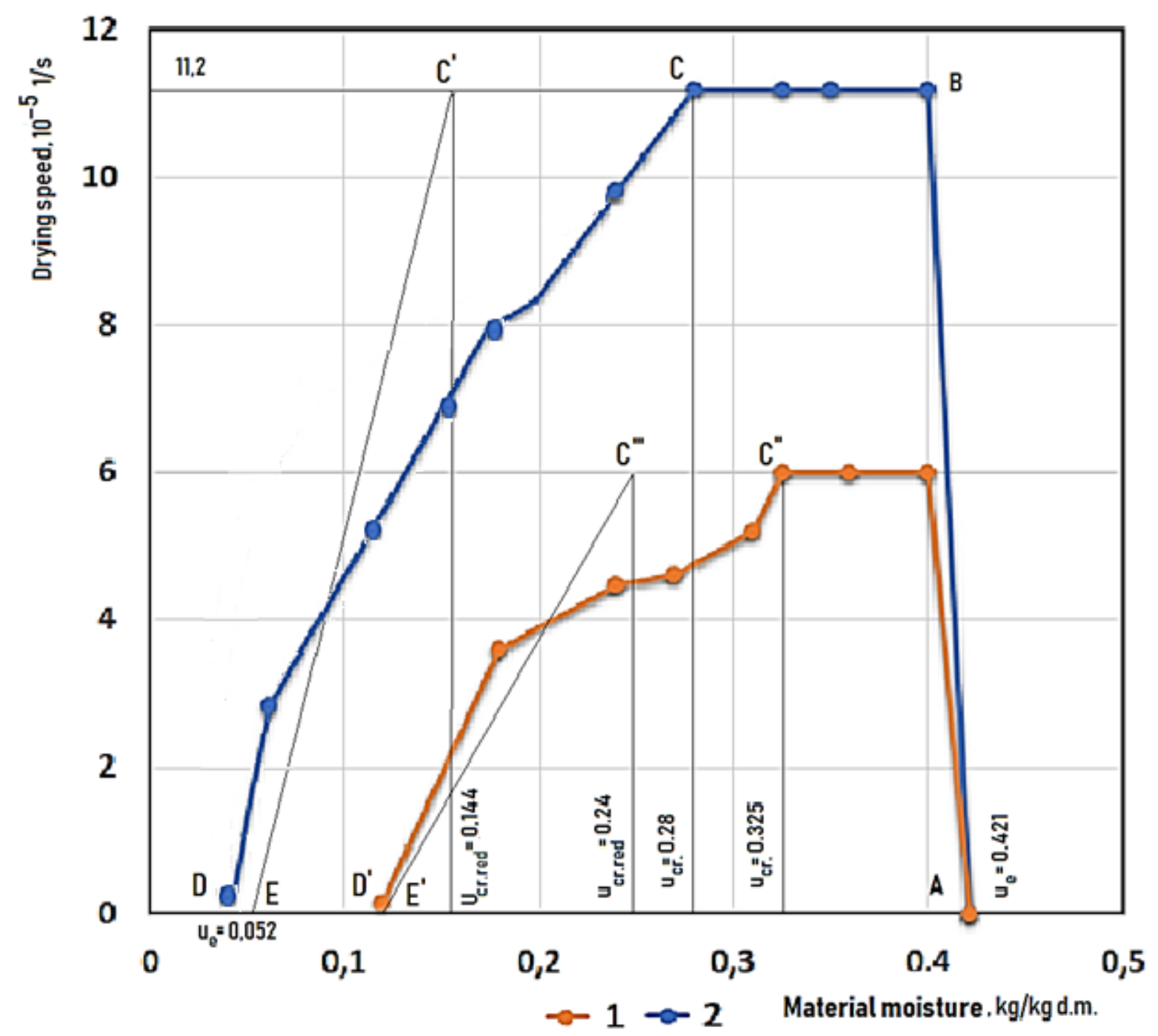

Fig. 5. Drying speed curves at pressure 0.6 MPa (1) and 0.8 MPa (2)

d.m.- dry material

\section{REFERENCES}

1. Lashkov VA, Instrumental equipment of the processes occurring at total and partial decrease of pressures of gas-vapor environment // Bulletin of Kazan
Technological University. 2011. Vol.14, No.8, -P. 210-215.

2. Potapov V.A., Gritsenko O.Yu., Ponomarenko Yu.O. Research of drying process in mass transfer modules under the influence of increased pressure // Progressive equipment and technologies 
of food production in restaurant industry and trade: collection of papers. Kharkiv State University of Food Technology and Trade, 2013, -P. 148-153.

3. Djuraev Kh.F., Rustamov E.S., Gafurov K.Kh. A new method of preparing apricots for drying // Materials of the international scientific and practical correspondence conference "Biotechnological, ecological and economic aspects of creating safe food for specialized purposes", Krasnodar, 2020.-P.438-441.

4. Djuraev Kh.F., Gafurov K.Kh., Rustamov E.S. New technology for processing fruits during drying // Problems and prospects of innovative technique and technology in agri-food chain. Proceedings scientific papers of the international conference. Tashkent, 2020.-P.332

5. Patent of Republic of Uzbekistan No. IAP 03373 - 30.05.2007, "Method of fruit drying".

6. Ginzburg, A.S. The basics of theories and techniques of food drying. - Moscow: Food Industry, 1973. $-528 \mathrm{p}$. 